\title{
Message from the President of ASCI
}

\author{
Tae-Hwan Lim
}

Received: 31 December 2008/ Accepted: 5 January 2009/Published online: 11 February 2009

(C) Springer Science+Business Media, B.V. 2009

The Asian Society of Cardiovascular Imaging was established on April 29, 2006 with the aim of advancing the science and art of cardiovascular imaging in Asia. Its inaugural scientific meeting was hosted in 2007 in Seoul, Korea with 545 participants and the second meeting was held in 2008 in Singapore with 602 participants. Our third meeting will be held in Tokyo, Japan, and the venue for our fourth meeting is Taipei, Taiwan. Through the annual scientific meetings, the Society aims to enhance the members' understanding and communication regarding the latest developments in the field of cardiovascular imaging and also to discover hidden talents in the Asian region. In order for a society to fully establish itself, it needs a journal which can carry the ideas and efforts of the Society to a broader audience. And I am pleased that we are able to make a start in our venture in creating our own journal with the help from the International Journal of Cardiovascular Imaging. I would like to thank Dr. Johan HC Reiber for his ever kind cooperation, and also I deeply appreciate our members who have contributed their dedicated research works to our special issue. Also I convey my heartfelt thanks to Dr. Yeon Hyeon
Choe and our reviewers who have contributed their precious time and effort to making this possible. I sincerely hope that this ASCI special issue will help to further the development of ASCI as a representative society dedicated to cardiovascular imaging in Asia.

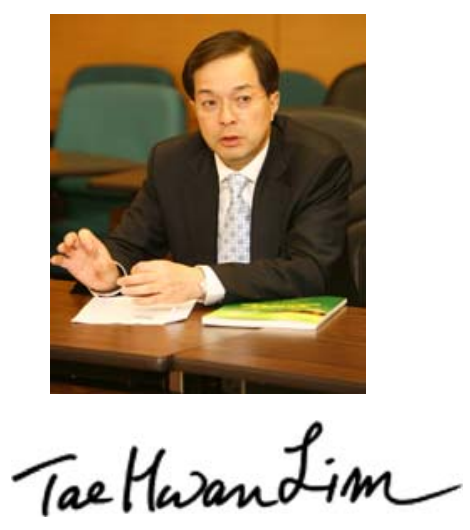

Tae-Hwan Lim, M.D., Ph.D.

President, Asian Society of Cardiovascular Imaging, Professor of Radiology,

Asan Medical Center, University of Ulsan College of Medicine

T.-H. Lim ( $\bowtie)$

Asian Society of Cardiovascular Imaging, Seoul, Korea

e-mail: office@asci-heart.org 